\title{
Evaluation of Patients' Satisfaction after Total Hip Arthroplasty (THA)
}

\author{
Toshio Ozawa RPT, $\mathrm{PhD}^{1,2)}$, KAZUHIKo SHIMIZU RPT, $\mathrm{PhD}^{3)}$ \\ 1) Graduate School of Medical Sciences, Kitasato University: 1-15-1, Kitasato, Sagamihara, \\ Kanagawa 228-8555, Japan. TEL +81 42-778-8111 \\ 2) Department of Rehabilitation, Eastern Japan Medical Center \\ 3) Department of Physical Therapy, School of Rehabilitation, Toyohashi Sozo University
}

J. Phys. Ther. Sci.

19: 139-143, 2007

\begin{abstract}
The satisfaction of patients after total hip arthroplasty (THA) was evaluated. At the same time, the physical function was evaluated in six hip joint groups of muscles as hip function recovery criteria of the Japanese Orthopaedics Association (JOA) Hip score, and also health-related quality of life (QOL) was evaluated by SF-36. The items that influenced a global satisfaction were related to the operation but not to activities, e.g., hobbies. The group of patients with high satisfaction of treatment showed higher scores for gait ability and activities of daily living (ADL) than the group of patients with poor satisfaction aid. The degree of role accomplishment at home was one of the important factors to affecting QOL. Development of rehabilitation and medical treatment in a long-term viewpoint is important for social participation of the patient. The satisfaction of the patient was related not only to the local hip disorder but also many other factors including psychological items. Therefore, the global evaluation of total outcomes of the medical service should be done include the degree of satisfaction of patients.
\end{abstract}

Key words: Total hip arthroplasty (THA), Patients' satisfaction, QOL

(This article was submitted Dec. 15, 2006, and was accepted Jan. 9, 2007)

\section{INTRODUCTION}

Total hip arthroplasty (THA) has been thought of as one of the best treatments for last stage coxarthrosis. Superior postoperative results of THA are usually obtained when it is compared with other joint reconstruction techniques.

There are many studies which have evaluated the outcomes of THA using the Japanese Orthopaedics Association Hip Score (JOA Hip score) ${ }^{1-3)}$. These studies, however, have usually been conducted from the viewpoint of medical staff, not from the patient's point of view ${ }^{4)}$. In this study, we evaluated the degree of satisfaction of patients who had received THA and compared it with the physical function (JOA Hip score) and also QOL (MOS Short-Form 36-Item Health Survey: SF-36) scores.

\section{SUBJECTS AND METHODS}

\section{Subjects}

The cases evaluated in this study were 84 female patients who had received THA for coxarthrosis at Ebina General Hospital, Hip Prosthesis and Rheumatism Center between October 1996 and September 2002. The lateral anterior approach in THA, and the operation was carried out using the Watson-Jones method. The implant used was made by Schutz und Glundei (S+G), ESKA company, and it was placed by dipping methods of a cementless type entirely. The average age of the patients was $59.5 \pm 8.9$ and consisted of age 11 patients: $40-49$, 36: 50-59, 24: 60-69, and 13: more than 70 years old. An interview was conducted three month after the operation. The post-operational period ranged from 3 to 48 months $(18.7 \pm 16.8) ; 23,17,15,10$, 
Table 1. The items used to measure patient satisfaction

\begin{tabular}{ll}
\hline Item & Questionnaires \\
\hline Total & Total satisfaction \\
Explanation & Explanation about THA by a doctor \\
Operation & Satisfaction of the operation \\
Pain reduction & Reduction of pain compared to pre-operation \\
Hospitalization life & The post-operative life in hospital \\
Joint mobility & Range of motion hip joint compared with pre-operation \\
Strength training & Post-operative muscle training \\
Floor movement & Including ability to stand up from floor, sweeping floor etc. \\
Gait & Satisfaction with walking and walking ability \\
Self-care activity & Putting on pants, socks, bathing, lavatory, pinching foot nail etc. \\
Role accomplishment & Roles such as house work work or working job \\
Hobby & Satisfaction with private life hobby activities \\
\hline
\end{tabular}

12 , and 7 patient passed $3,6,12,24,36$, and 48 month after operation, respectively.

\section{METHODS}

The questionnaires were conducted by personnel who had not contributed to the treatment of the patients and took place with the patients informed consent.

i) The items measuring patient's degree of satisfaction after THA are shown in Table 1.

ii) Physical function evaluation of each patient was also recorded using the JOA Hip score sheet. Muscle force evaluation using the manual muscle test method was carried out for six group muscles around the hip (flexors, extensors, abductors, adductors, internal and external rotators).

iii) In addition, we evaluated pain, range of motion, and muscle strength on both the operated and non-operated side, separately. The healthrelated QOL was evaluated by using the Japanese ver.1.2 of SF-36, which is an internationally accepted measure. The patients filled in the SF-36 questionnarires ${ }^{5)}$.

To evaluate the differences between groups and factors, we used the one way analysis of variance (ANOVA; SPS 12.0 J for Windows) and Kendall's procedure. The significance level was chosen as a $p$-vale of 0.05 .

This study was approved by the medical ethics committee of our hospital.

\section{RESULTS}

\section{Patients' degree of satisfaction after THA}

Table 2 shows the mean and standard deviation for each item of patients' satisfaction with high and low satisfaction groups, which were elicited from the mean value. Analysis between age groups and the factors found that there were no statistically significant differences between any age group or any factor (n.s.). Comparison found groups between house-wives (54 cases) and persons with jobs ( 30 cases) there were no differences between these two groups in any factor.

\section{JOA Hip score and the muscle force}

Although the patient group with high satisfaction (high satisfaction group) showed no statistical difference in pain on both operated and nonoperated sides, the patient group with poor satisfaction (poor satisfaction group) showed a significant difference in pain both: the patients in the high satisfaction group felt less pain, compared to those in poor satisfaction group. On the other hand, ROM was significantly lower in the operated side than in the non-operated side in both groups, but it was higher in the high satisfaction group than in the poor satisfaction group $(p<0.05)$. Gait ability and ADL showed higher scores in the high satisfaction group than in the poor satisfaction group.

The group with high satisfaction showed a high JOA hip score for pain, ROM, gait ability, and ADL (Table 3). However, poor satisfaction with regard to the recovery of the six groups of the hip circumference muscles, a significant difference was 
Table 2. Patients' degree of satisfaction after THA

\begin{tabular}{lccc}
\hline Item & All patients & Group with high satisfaction & Group with poor satisfaction \\
\hline Total & $7.99 \pm 2.54$ & $9.08 \pm 0.91$ & $4.50 \pm 2.93$ \\
Explanation & $7.80 \pm 2.36$ & $9.12 \pm 0.90$ & $4.85 \pm 1.87$ \\
Operation & $9.38 \pm 1.32$ & $10.0 \pm 0.00$ & $7.64 \pm 1.59$ \\
Pain reduction & $8.75 \pm 2.76$ & $9.82 \pm 0.39$ & $5.73 \pm 4.08$ \\
Hospitalization life & $7.12 \pm 3.28$ & $8.92 \pm 0.90$ & $4.03 \pm 3.58$ \\
Joint mobility & $7.32 \pm 3.27$ & $9.15 \pm 0.93$ & $4.19 \pm 3.47$ \\
Strength training & $7.98 \pm 2.43$ & $9.30 \pm 0.58$ & $5.32 \pm 2.39$ \\
Floor movement & $7.14 \pm 3.10$ & $9.36 \pm 0.82$ & $4.32 \pm 2.59$ \\
Gait & $8.14 \pm 2.63$ & $8.91 \pm 0.29$ & $6.10 \pm 2.66$ \\
Self-care activity & $7.70 \pm 2.69$ & $9.27 \pm 0.87$ & $4.72 \pm 2.45$ \\
Role accomplishment & $7.57 \pm 3.31$ & $9.30 \pm 0.87$ & $4.61 \pm 3.83$ \\
Hobby & $6.99 \pm 3.74$ & $8.93 \pm 1.20$ & $2.65 \pm 3.87$ \\
\hline
\end{tabular}

Mean \pm S.D., in arbitrary unit, $p<0.05$

Table 3. JOA Hip Score

\begin{tabular}{lcccccccc}
\hline & \multicolumn{2}{c}{ Pain } & & \multicolumn{2}{c}{ ROM } & Gait & ADL & Total \\
\cline { 2 - 3 } & $\begin{array}{c}\text { Operated } \\
\text { side }\end{array}$ & $\begin{array}{c}\text { Un-operated } \\
\text { side }\end{array}$ & $\begin{array}{c}\text { Operated } \\
\text { side }\end{array}$ & $\begin{array}{c}\text { Un-operated } \\
\text { side }\end{array}$ & & & & \\
\hline $\begin{array}{l}\text { Patients with } \\
\text { high satisfaction }\end{array}$ & $40.0 \pm 00.0$ & $40.0 \pm 00.0$ & $16.1 \pm 4.2$ & $18.1 \pm 3.5$ & $18.6 \pm 2.3$ & $19.4 \pm 0.9$ & $90.3 \pm 12.3$ \\
$\begin{array}{l}\text { Patients with } \\
\text { poor satisfaction }\end{array}$ & $33.9 \pm 3.6$ & $28.4 \pm 8.5$ & $12.3 \pm 1.7$ & $13.3 \pm 2.7$ & $11.9 \pm 3.3$ & $14.5 \pm 2.1$ & $77.8 \pm 6.3$ \\
All patients & $37.9 \pm 3.6$ & $36.3 \pm 7.2$ & $14.8 \pm 3.8$ & $16.5 \pm 3.8$ & $16.3 \pm 4.0$ & $17.7 \pm 2.7$ & $86.7 \pm 8.4$ \\
\hline
\end{tabular}

Mean \pm S.D., $p<0.05$

not shown between high and low groups.

\section{Relation of SF-36 with satisfaction}

In the health-related quality of life index, all eight items revealed significantly higher scores in the high satisfaction group than those in the group with poor satisfaction (Table 4).

The difference between the high and poor satisfaction groups was the biggest in role physical (RP) and followed by role emotional (RE), social functioning (SF), vitality (VT), body pain (BP), physical function (PF), general health $(\mathrm{GH})$, and the lowest in mental health (MH). The RP and RE differed between the two groups and the differences of average scores were more than 30 points.

Although the mental health $(\mathrm{MH})$ showed the minimum difference the other psychological items, i.e., role emotional (RE), social functioning (SF), and vitality (VT) showed the four major biggest differences. The biggest difference in score between the two groups was observed in role physical (RP). Table 5 shows the outcomes of correlation coefficients among patients' satisfaction and QOL (SF-36).

\section{DISCUSSION}

Patients' satisfaction with THA was largely dependent on the pain reduction, joint mobility and gait ability. The patients with low scores for gait and ADL showed poor evaluation of almost all the used items to evaluate satisfaction ${ }^{6}$. This can be explained by the restriction of activities relating to the satisfaction of the patients. A patient's expectation of THA is not only improvement in pain reduction but also joint mobility, floor movement, gait ability, self-care activity, role accomplishment, and even hobby, since they contribute to the improvement of daily life and social activity.

The recovery of muscle strength after operation is slower than the other parameters, e.g., pain 
Table 4. SF-36 items and grouping of patients' satisfaction to role of accomplishment

\begin{tabular}{cccc}
\hline & High satisfaction group & Low satisfaction group & All patients \\
\hline PF & $83.06 \pm 14.58$ & $65.00 \pm 19.02$ & $76.40 \pm 18.46$ \\
RP & $79.25 \pm 19.74$ & $44.80 \pm 39.83$ & $66.57 \pm 38.08$ \\
BP & $74.58 \pm 19.74$ & $55.90 \pm 22.33$ & $67.69 \pm 22.51$ \\
GH & $68.30 \pm 16.71$ & $52.71 \pm 19.12$ & $62.55 \pm 19.12$ \\
VT & $73.77 \pm 18.13$ & $53.55 \pm 19.50$ & $66.31 \pm 20.97$ \\
SF & $87.97 \pm 16.25$ & $65.32 \pm 25.56$ & $79.61 \pm 22.86$ \\
RE & $88.05 \pm 27.81$ & $58.60 \pm 46.12$ & $77.18 \pm 38.18$ \\
MH & $77.31 \pm 19.44$ & $66.19 \pm 17.28$ & $73.21 \pm 19.34$ \\
\hline
\end{tabular}

PF: Physical Function RP: Role Physical BP: Body Pain GH: General Health VT: Vitality SF: Social Function RE: Role Emotion MH: Mental Health. Mean \pm S.D. $p<0.05$

Table 5. Correlation coefficients of patients' satisfaction with items of SF-36

\begin{tabular}{lllllllll}
\hline & PF & RP & BP & GH & VT & SF & RE & MH \\
\hline Total & $0.38^{* *}$ & 0.19 & 0.25 & 0.24 & $0.27^{*}$ & $0.23^{* *}$ & 0.19 & 0.18 \\
Explanation & 0.08 & 0.05 & 0.08 & 0.06 & 0.11 & 0.08 & 0.05 & 0.13 \\
Operation & $0.26^{* *}$ & 0.11 & $0.20^{*}$ & $0.19^{*}$ & $0.21^{* *}$ & $0.17^{*}$ & 0.12 & $0.23^{* *}$ \\
Pain reduction & $0.29^{* *}$ & 0.16 & $0.37^{* *}$ & 0.12 & $0.26^{*}$ & $0.25^{*}$ & 0.09 & 0.20 \\
Hospitalization life & 0.16 & 0.05 & 0.15 & 0.10 & 0.12 & 0.06 & 0.04 & 0.13 \\
Joint mobility & $0.36^{* *}$ & $0.23^{* *}$ & $0.37^{* *}$ & 0.23 & $0.32^{* *}$ & $0.32^{* *}$ & $0.27 * *$ & 0.26 \\
Strength training & 0.22 & 0.05 & 0.14 & 0.25 & 0.21 & 0.09 & 0.14 & 0.27 \\
Floor movement & $0.18^{*}$ & 0.03 & 0.08 & 0.17 & 0.11 & 0.14 & 0.04 & 0.08 \\
Gait & $0.32^{* *}$ & 0.16 & $0.26^{* *}$ & 0.26 & $0.29^{* *}$ & $0.28^{* *}$ & $0.16^{*}$ & $0.23^{*}$ \\
Self-care activity & $0.29^{* *}$ & 0.13 & 0.18 & 0.17 & $0.21^{*}$ & 0.25 & 0.11 & 0.14 \\
Role accomplishment & $0.39^{* *}$ & $0.32^{* *}$ & $0.31^{* *}$ & $0.30^{* *}$ & $0.40^{* *}$ & $0.34^{* *}$ & $0.20^{* *}$ & $0.29^{* *}$ \\
Hobby & $0.22^{*}$ & $0.23^{* *}$ & 0.18 & 0.23 & $0.25^{*}$ & $0.23^{* *}$ & 0.23 & 0.25 \\
\hline
\end{tabular}

Items of SF-36: abbreviations as per Table 4.

$* p<0.05, * * p<0.01$.

reduction and joint mobility, and it usually takes from 6 to 12 months. Therefore, the patients could not recognize an improvement of their satisfaction in these parameters.

The differences in QOL between groups consisting of patients with high satisfaction and with poor satisfaction were apparent. Also, patients who had less restriction on social activity showed a higher QOL score. Accordingly, the ability to participate in social activity is a significant factor for increasing satisfaction of patients. Previously, we proposed a model for predicting recovery of ability of function after THA. The model explained functional items up to $70 \%$ and also QOL in daily life by ability up to approximately $60 \%{ }^{7,8)}$.

Medical service is provided by a variety of techniques of specialists and also sophisticated instruments in collaborative work. The present study evaluated outcomes of treatment from the view point of doctors with less respective of patient's view point. This study found that improving the satisfaction of patients leads to the total successfulness of the medical service. An evaluation system for performance of treatment should be established which takes into account into not only medical view points but also patients' satisfaction, to increase the patients' satisfaction with the results in the increment of total value of medical service.

\section{ACKNOWLEDGEMENTS}

I would like to thank all the patients who participated in this study for their kind cooperation. 
I would also like to thank all physical therapists and other staff members for their great help in engaging in this study. Special thanks should be giving to Professor Toshiro Futami, Kitasato University Orthopedics, for his invaluable support and discussions regarding.

\section{REFERENCES}

1) Japanese Orthopaedic Association Hip Joint Assessment Criteria Committee: Comparative study of therapies for coxarthrosis and osteoarthrosis: creation of results assessment standards and assessment of long-term prognosis results. J Orthop Sci, 1971, 45: 813-833 (in Japanese)

2) Japanese Orthopaedic Association: Evaluation Chart of Hip Joint Functions. J Jpn Orthop Assoc, 1995, 69: $860-867$.
3) Fukuda K, Hamanishi C: Treatment for osteoarthritis of the hip joint. Sogo Rihabiriteshon, 2001, 29: 207212 (in Japanse).

4) Sodermann P: On the validity of the results from the Swedish National Total Hip Arthroplasty register. Acta Orthop Scand Suppl, 2000, 71: 1-33.

5) Fukuhara S, Suzukamo Y, Bito S, et al.: SF-36 Japanese version manual (Ver. 1.2). Tokyo: Public Health Research Center Foundation, 2001 (in Japanese)

6) Tsushima E: Physical therapy for disability of activities of daily living in patients with osteoarthritis of the hip. J Phys Ther, 1997, 14: 647-652.

7) Whyte J: Distinctive Methodology Challenges. In: Assessing Medical Rehabilitation Practices. Fuhrer MJ (ed.), Baltimore: Paul H. Brooks Publishing, 1997, pp 43-60.

8) Whyte J: Toward a methodology for rehabilitation research. Am J Phys Med, 1994, 331: 821-827. 